\title{
The Decomposition Mechanism of Hexanitrohexaazaisowurtzitane (Cl-20) By Coupled Computational And Experimental Study
}

Macharla Arun Kumar ${ }^{\ddagger}$, Parimi Ashutosh ${ }^{\ddagger}$, Anuj A.Vargeese*

Advanced Center of Research in High Energy Materials (ACRHEM), University of Hyderabad, Hyderabad 500 046, India

*Email: aav@uohyd.ac.in

$\ddagger$ The two authors contribute equally to this work

\section{Table of Contents}

1. Molecular Electro Static Potential (MESP) of 4,10-Dinitro-2,6,8,12-tetraoxa-4,10-

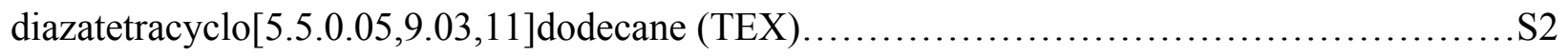

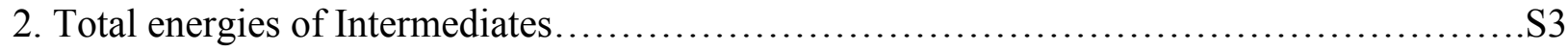

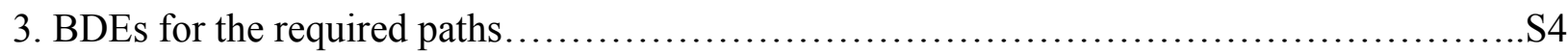

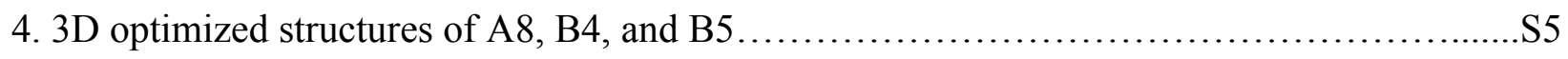

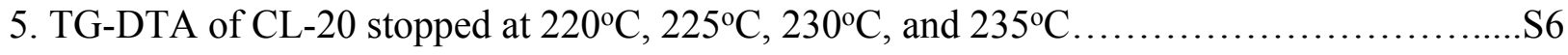

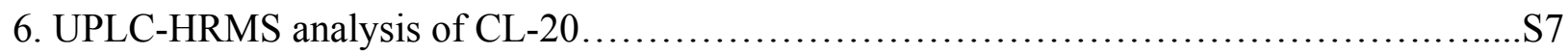

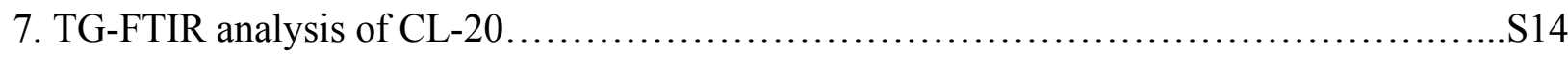




\section{Molecular Electro Static Potential (MESP) of 4,10-Dinitro-2,6,8,12-tetraoxa-4,10- diazatetracyclo[5.5.0.05,9.03,11]dodecane (TEX)}

The MESP of TEX shows the availability of electrons with the oxygen atoms in the nitro-groups, as well as the oxygen atoms in the pentagonal rings. The external indication of electron-rich regions in the MESP of TEX mean that there is no entrapment of electrons inside the cage. This kind of behavior is absent with respect to CL-20, as there is no clear indication of electrons outside the cage, which can only mean that the electrons are trapped inside the cage, in CL-20.

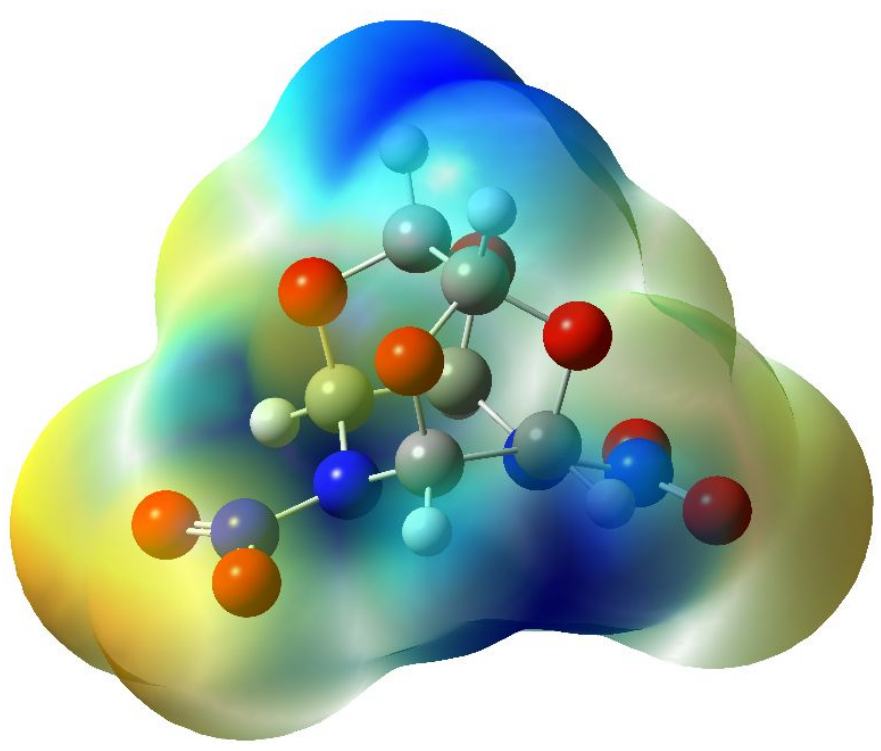

Figure S1. MESP of TEX (white::hydrogen; blue::nitrogen; grey::carbon; red::oxygen) 


\section{Total energies of Intermediates}

Table S1. Total Energies of Intermediates

\begin{tabular}{cc}
\hline Intermediate & $\begin{array}{c}\text { Total Energy } \\
\text { (Hartree/particle) }\end{array}$ \\
\hline CL-20 & -1791.4654 \\
A1 & -1586.2859 \\
A2 & -1381.2207 \\
A3 & -1176.0534 \\
A4 & -970.9353 \\
A5 & -765.7602 \\
A6 & -560.6669 \\
A7 & -1176.0475 \\
A8 & -969.5628 \\
B1 & -1585.6610 \\
B2 & -1379.8517 \\
B3 & -1174.6845 \\
B4 & -969.5628 \\
B5 & -764.3642 \\
B6 & -559.3456 \\
B7 & -295.1198 \\
C1 & -1116.7637 \\
C2 & -558.3977 \\
F1 & -674.5427 \\
\hline
\end{tabular}




\section{BDEs for the required paths}

Table S2. BDEs for the required paths

\begin{tabular}{|c|c|c|}
\hline Path & $\begin{array}{c}\text { Formed } \\
\text { Intermediate }\end{array}$ & $\begin{array}{c}\text { BDE }^{*} \\
\left({\left.\mathrm{~kJ} . \mathrm{mol}^{-1}\right)}^{-1}\right.\end{array}$ \\
\hline $\mathrm{CL}-20-\mathrm{NO}_{2}$ & $\mathrm{~A} 1$ & 132.84 \\
\hline $\mathrm{A} 1-\mathrm{NO}_{2}$ & $\mathrm{~A} 2$ & -167.24 \\
\hline $\mathrm{A} 2-\mathrm{NO}_{2}$ & A3 & 100.81 \\
\hline $\mathrm{A} 3-\mathrm{NO}_{2}$ & A4 & -28.35 \\
\hline $\mathrm{A} 4-\mathrm{NO}_{2}$ & A5 & 121.3 \\
\hline $\mathrm{A} 5-\mathrm{NO}_{2}$ & A6 & -93.46 \\
\hline $\mathrm{A} 2-\mathrm{NO}_{2}$ & A7 & 116.3 \\
\hline $\mathrm{A} 7-\mathrm{NO}_{2}$ & A8 & 75.35 \\
\hline A8 & $\begin{array}{c}\mathrm{F} 1+\mathrm{N}_{2}+2 \\
\mathrm{HCN}\end{array}$ & 494.9 \\
\hline $\begin{array}{l}\text { CL-20 - } \\
\text { HONO }\end{array}$ & B1 & 149.65 \\
\hline B1 - HONO & $\mathrm{B} 2$ & 162.52 \\
\hline $\mathrm{B} 2-\mathrm{NO}_{2}$ & B3 & 100.56 \\
\hline $\mathrm{B} 3-\mathrm{NO}_{2}$ & B4 & 18.9 \\
\hline $\mathrm{B} 4-\mathrm{NO}_{2}$ & B5 & 183.0 \\
\hline $\mathrm{B} 5-\mathrm{NO}_{2}$ & B6 & -289.59 \\
\hline B4 & $\mathrm{F} 1+\mathrm{B} 7$ & 261.76 \\
\hline CL-20 & $\mathrm{F} 1+\mathrm{C} 1$ & 261.76 \\
\hline $\mathrm{C} 1$ & $2 \mathrm{C} 2$ & 83.23 \\
\hline
\end{tabular}




\section{3D optimized structures of A8, B4, and B5}

To satisfy their respective valances the nitrogen atoms have come closer to have an interaction in the following structures.

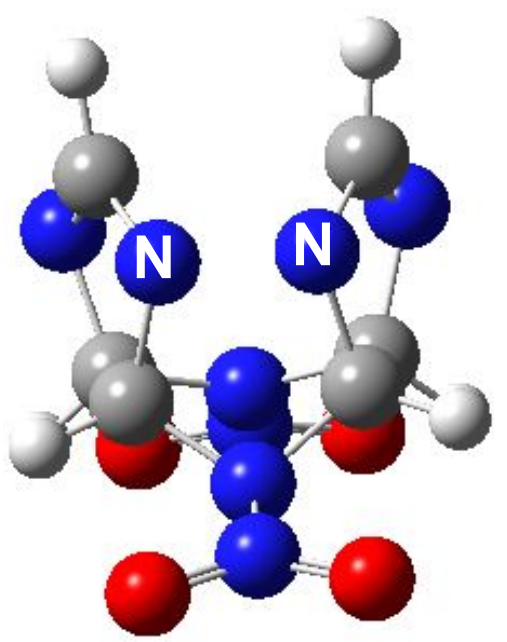

A8

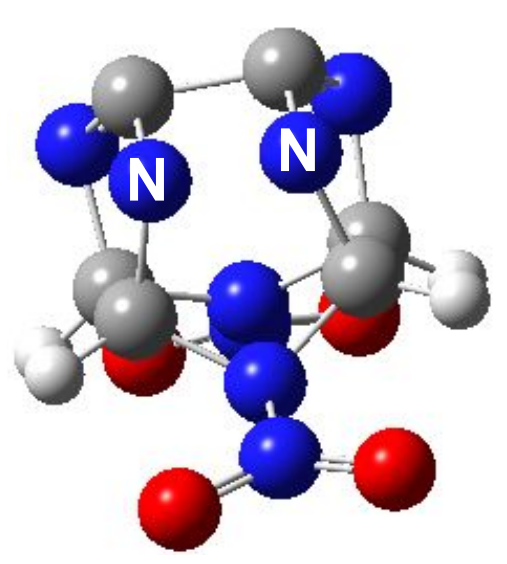

B4

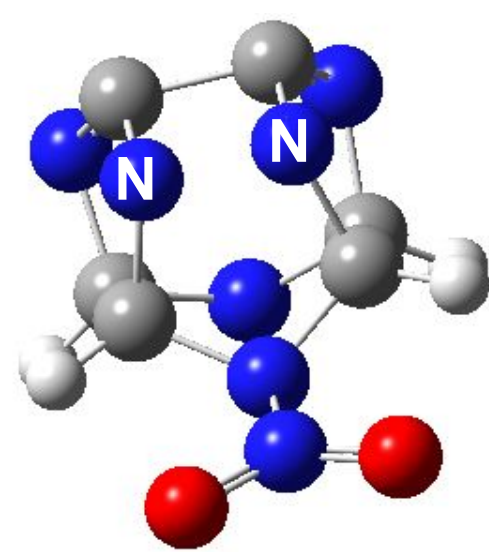

B5

Figure S2. 3D optimized structures 
5. TG-DTA of CL-20 stopped at $220^{\circ} \mathrm{C}, 225^{\circ} \mathrm{C}, 230^{\circ} \mathrm{C}$, and $235^{\circ} \mathrm{C}$
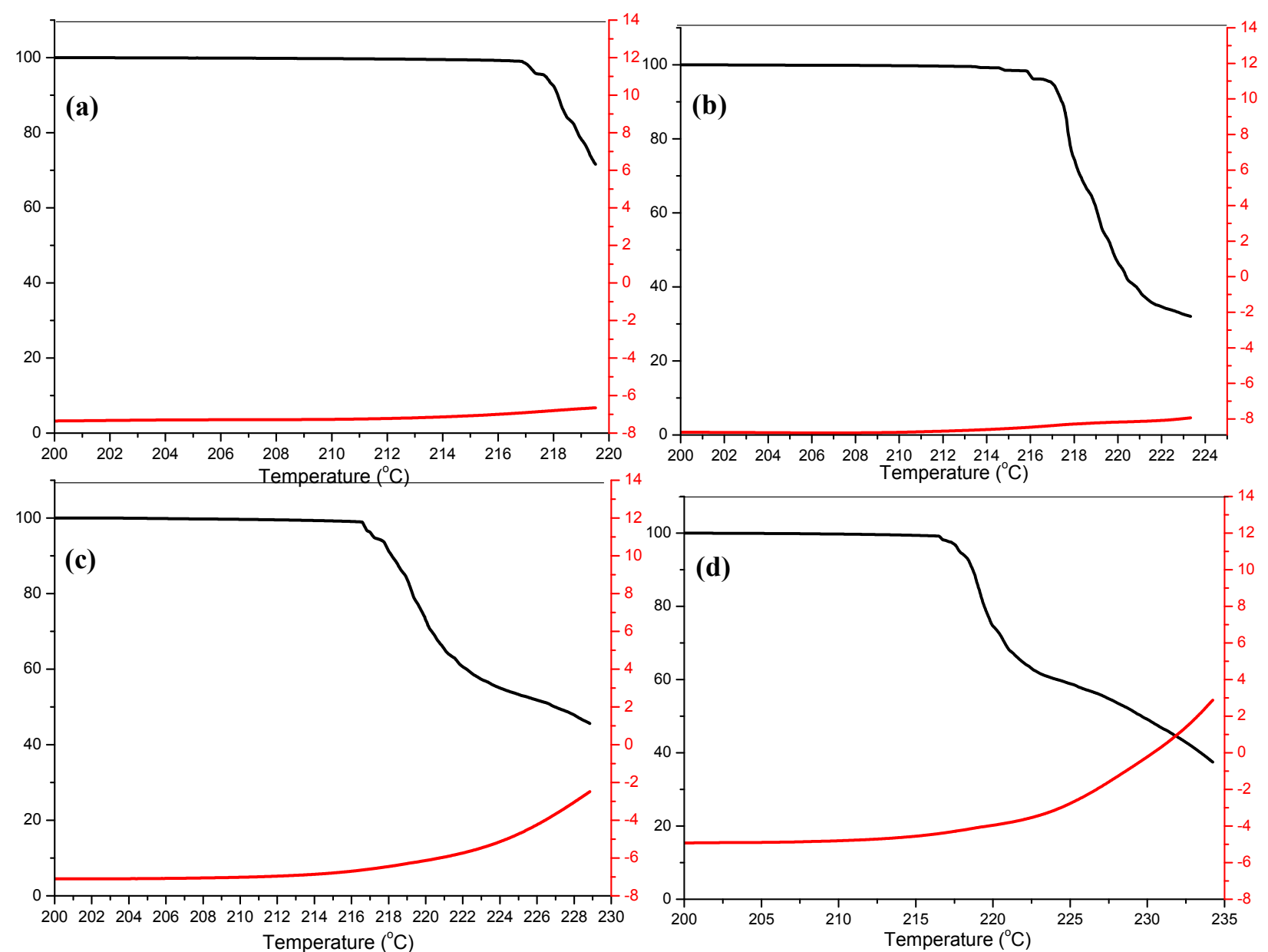

Figure S3. TG-DTA curve of thermal decomposition of CL-20 stopped at (a) $220^{\circ} \mathrm{C}$, (b) $225^{\circ} \mathrm{C}$, (c) $230^{\circ} \mathrm{C}$, and (d) $235^{\circ} \mathrm{C}$ at the heating rate of $3{ }^{\circ} \mathrm{C} / \mathrm{min}$ 
6. UPLC-HRMS analysis of CL-20

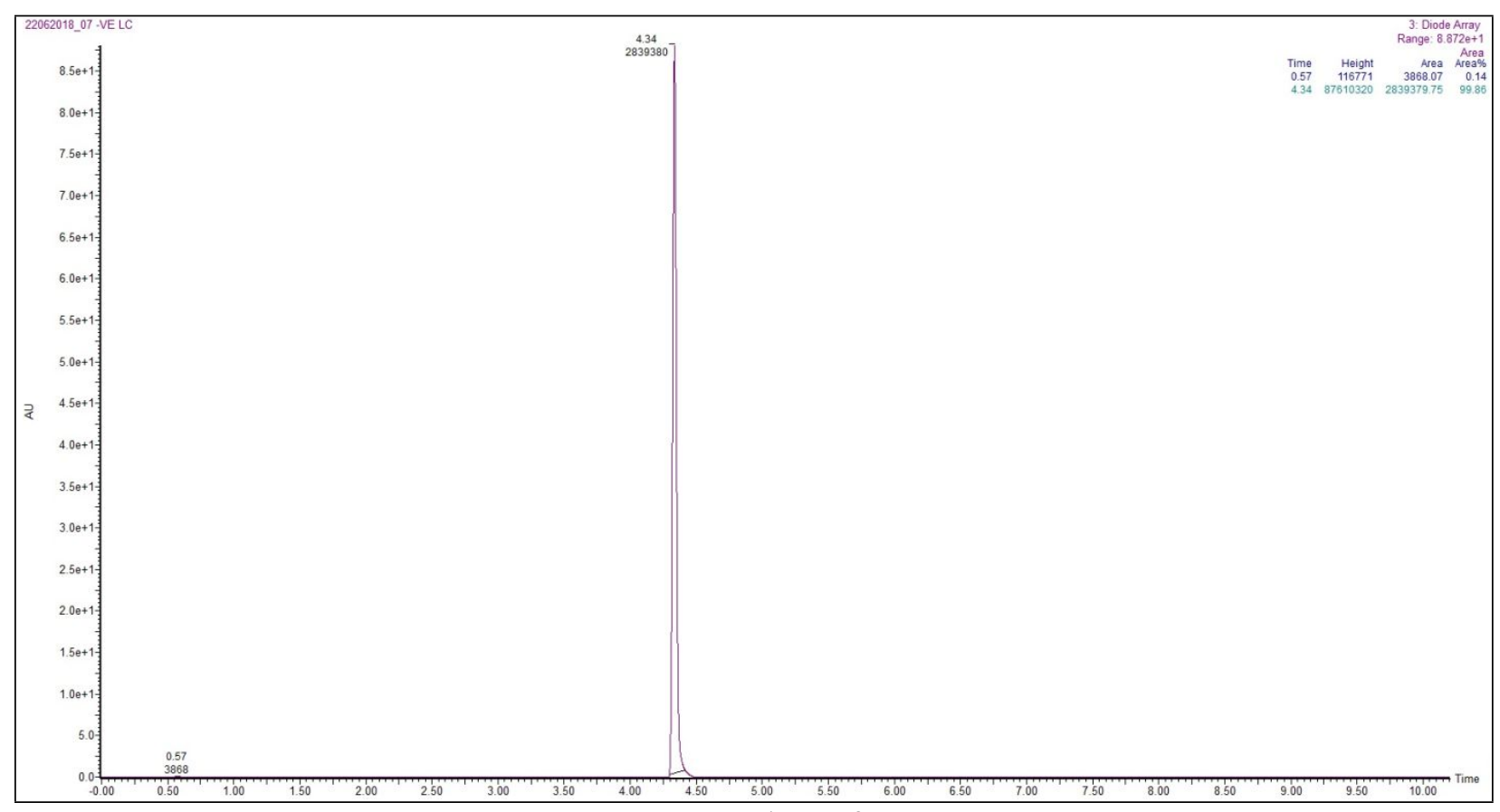

Figure S4. LC data of CL-20. 


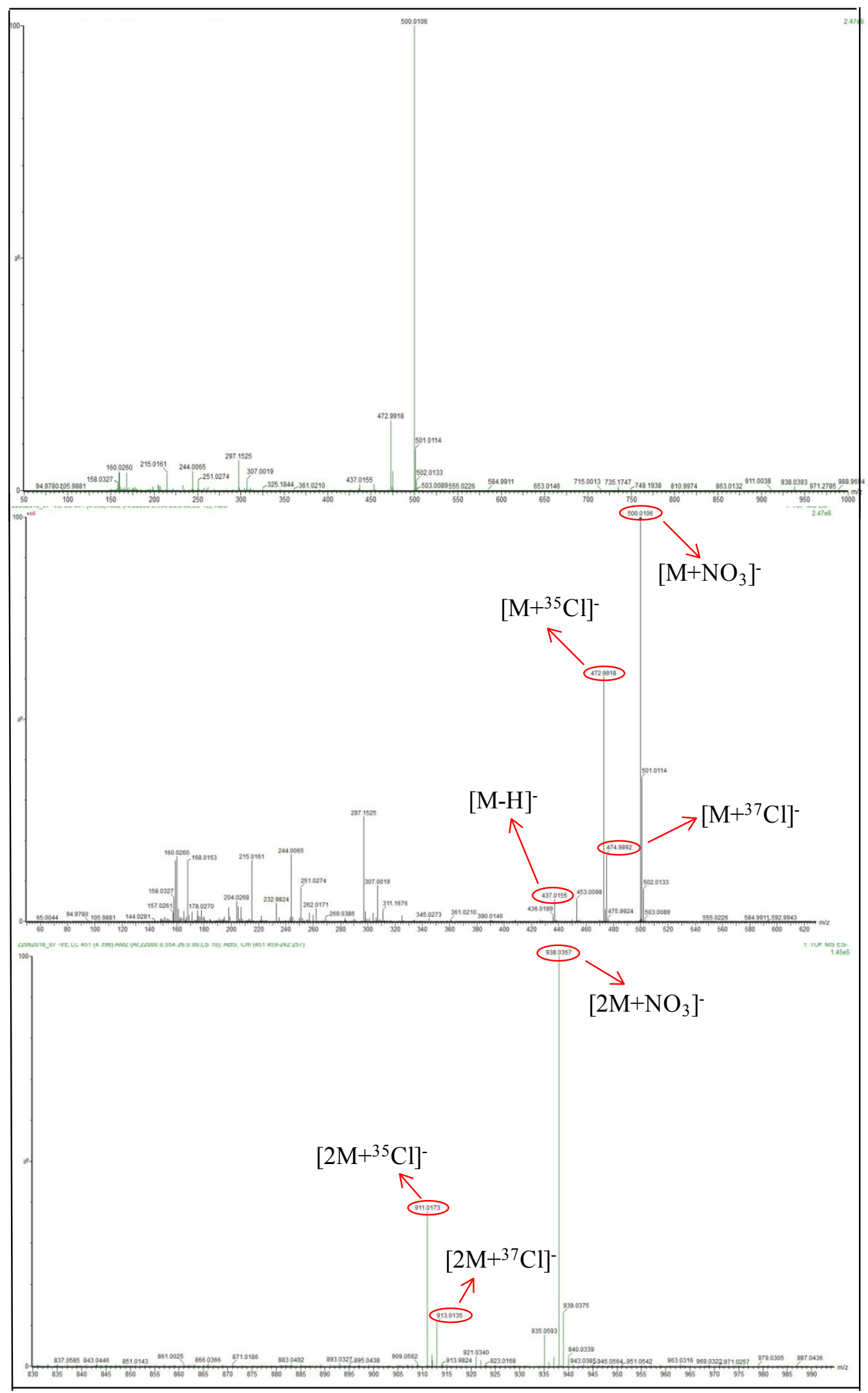

Figure S5. Mass spectra of CL-20 for the chromatographic peak at 4.34 minutes 


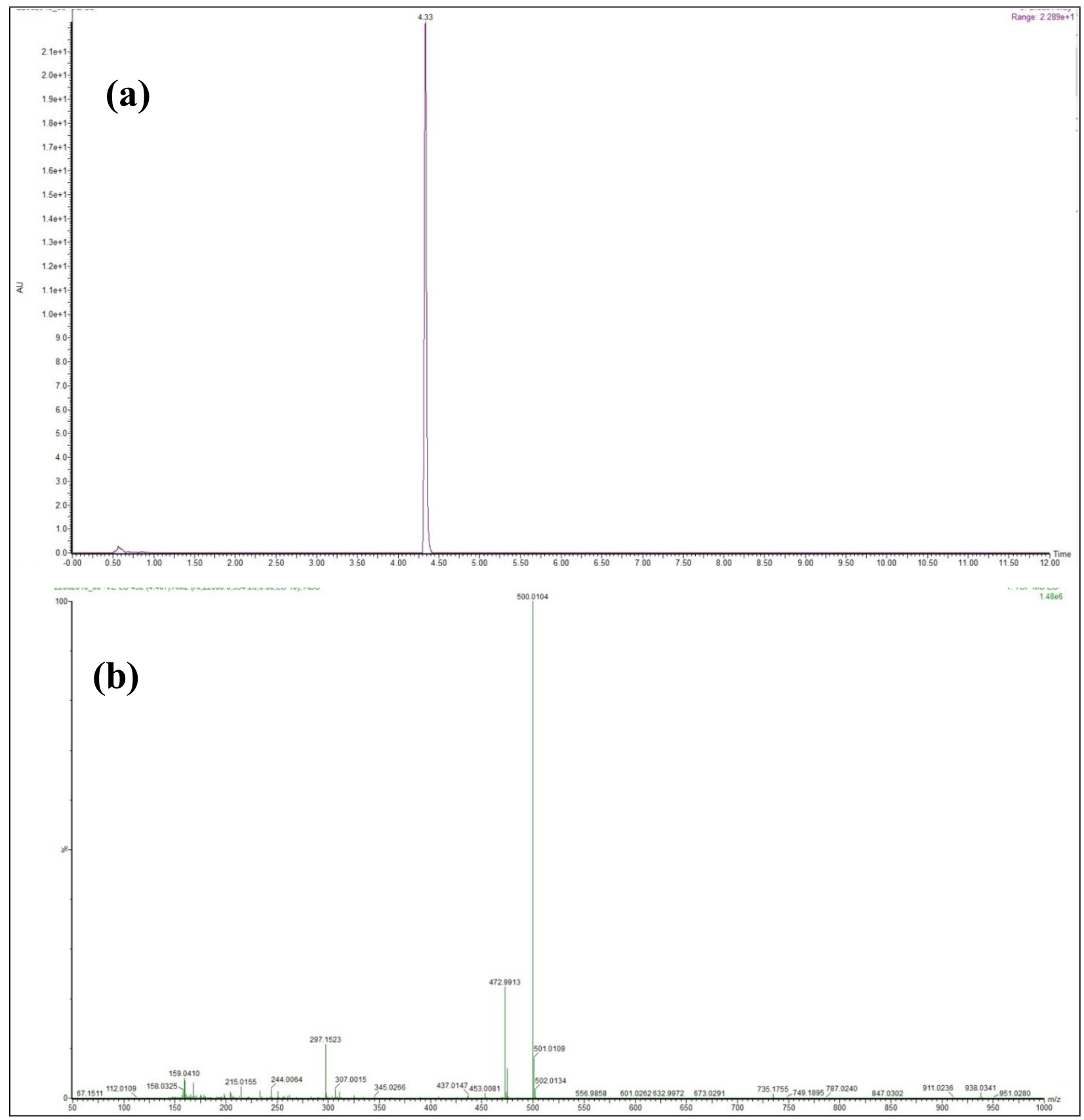

Figure S6. (a) LC data of CL-20-220. (b) Mass spectra for the chromatographic peak at 4.33 minutes 


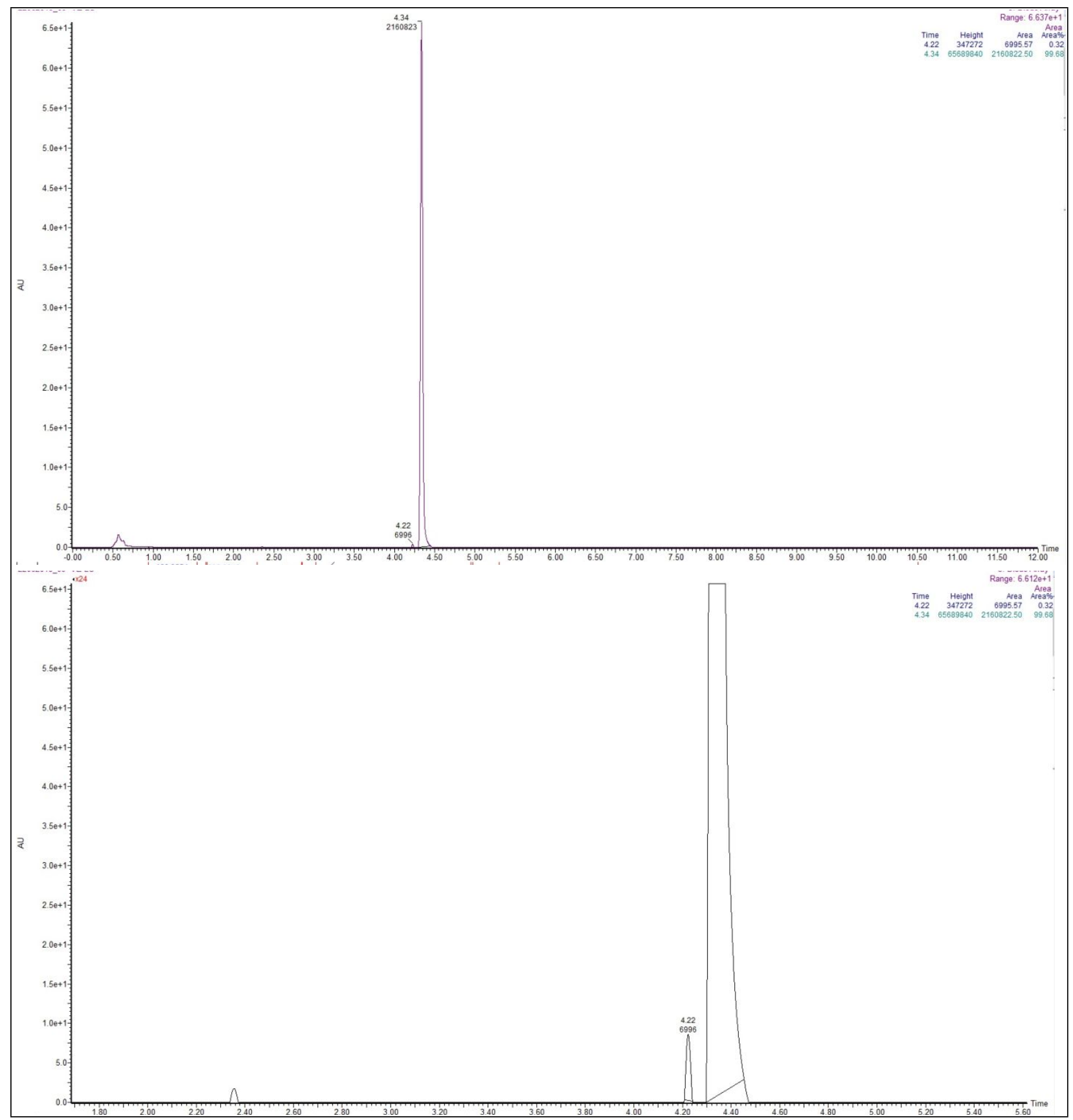

Figure S7. LC data of CL-20-225. 


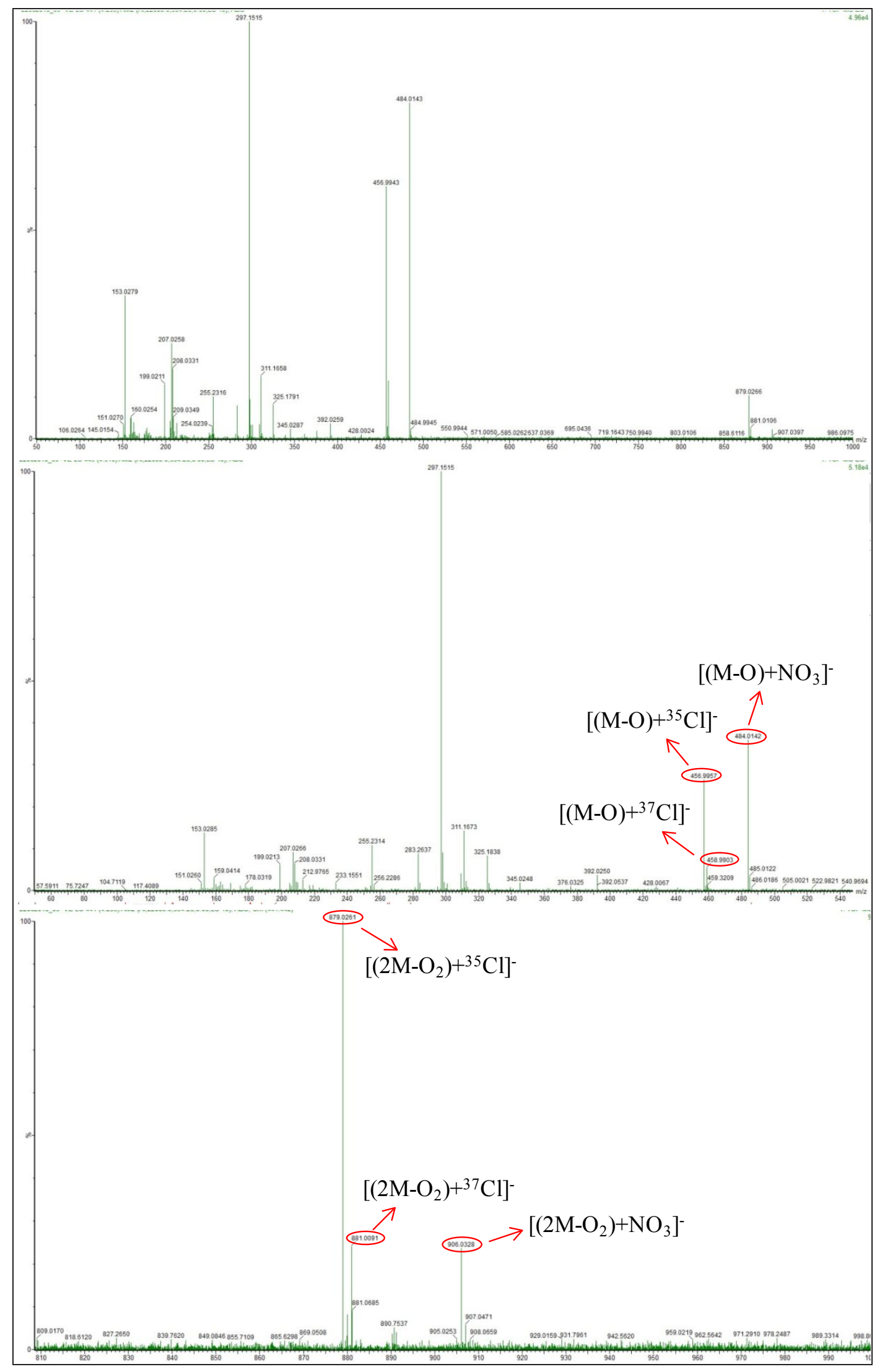


Figure S8. Mass spectra of CL-20-225 for the chromatographic peak at 4.22 minutes

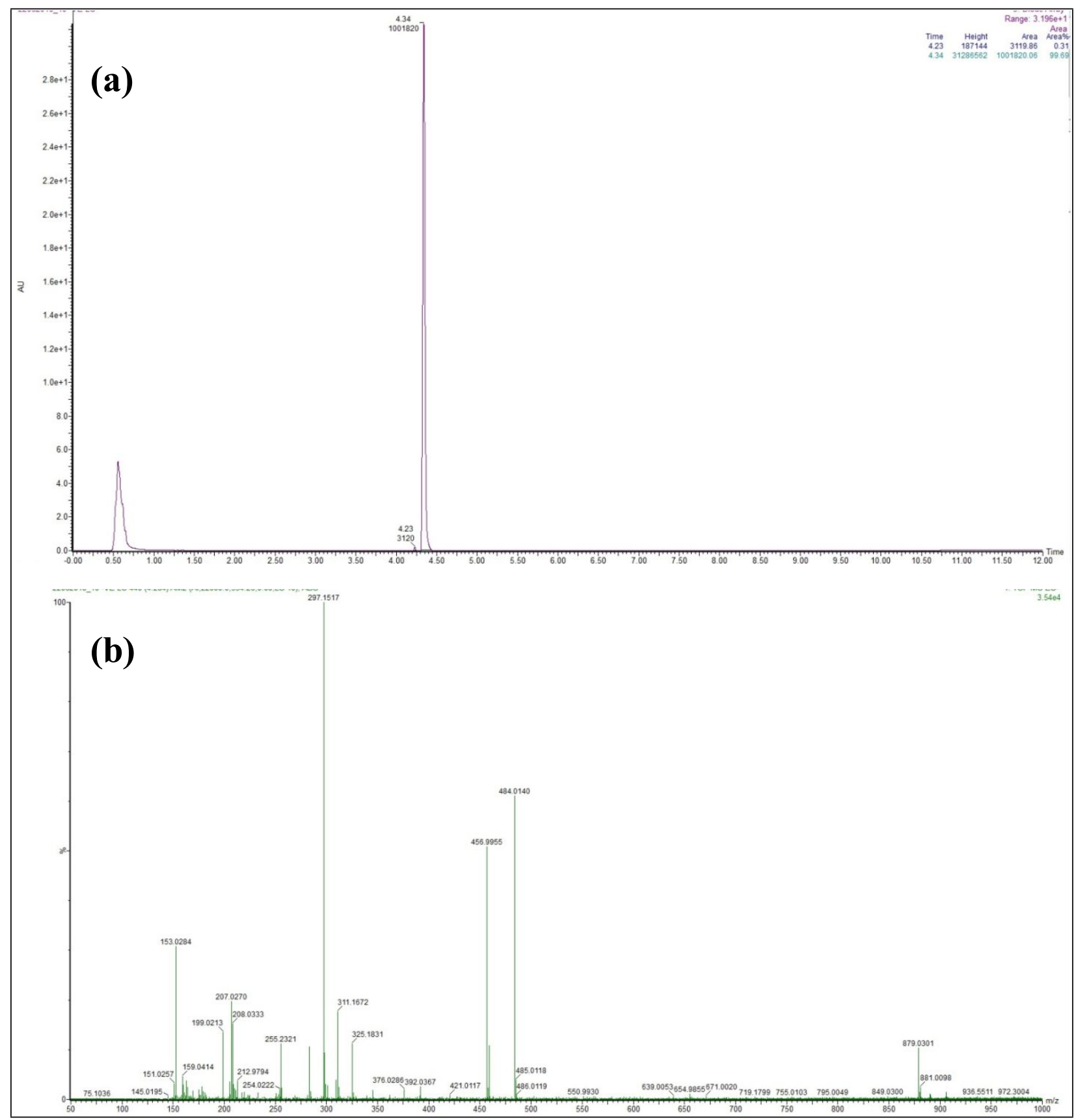

Figure S9. (a) LC data of CL-20-230. (b) Mass spectra for the chromatographic peak at 4.23 minutes 


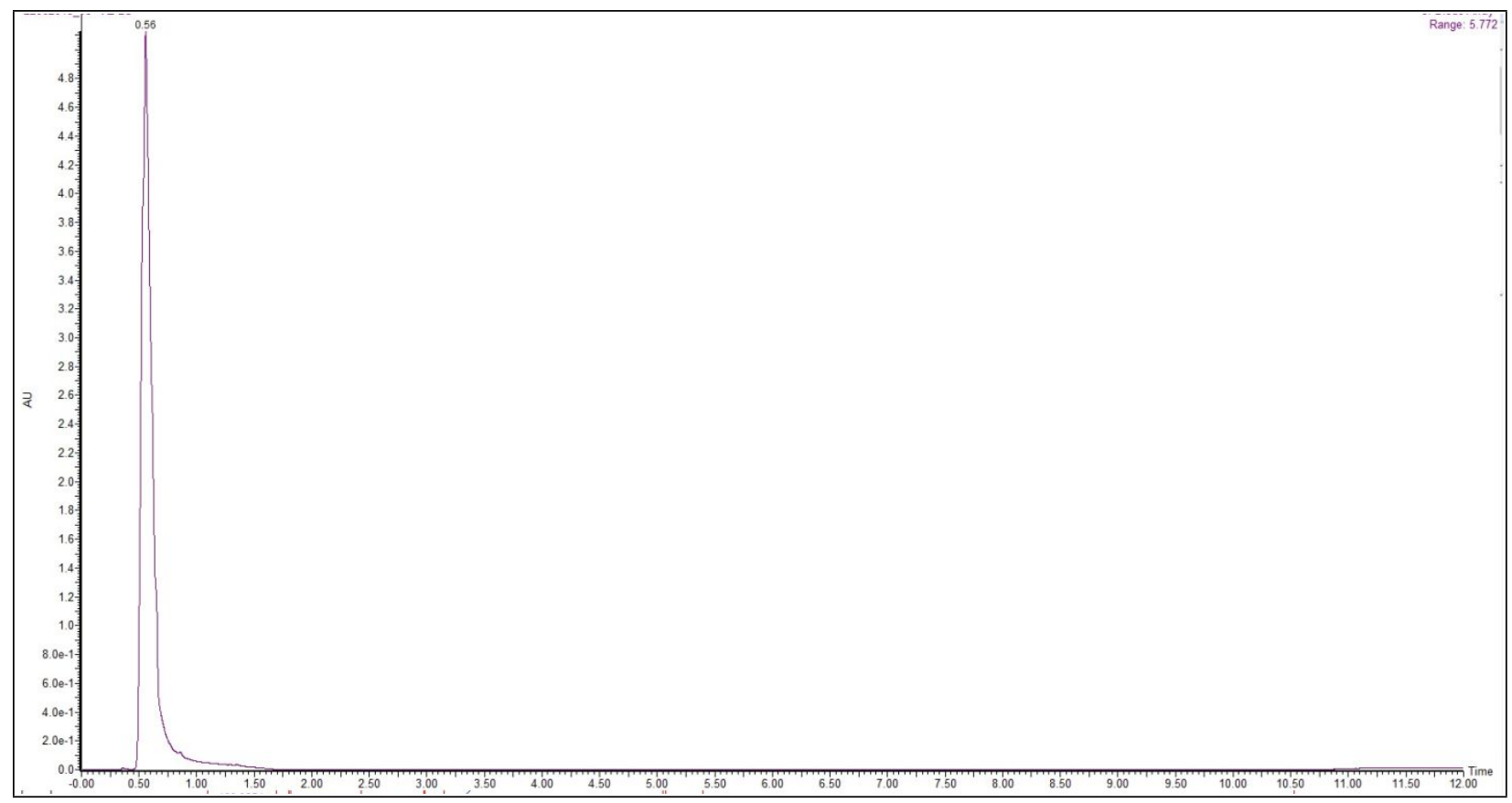

Figure S10. LC data of CL-20-235.

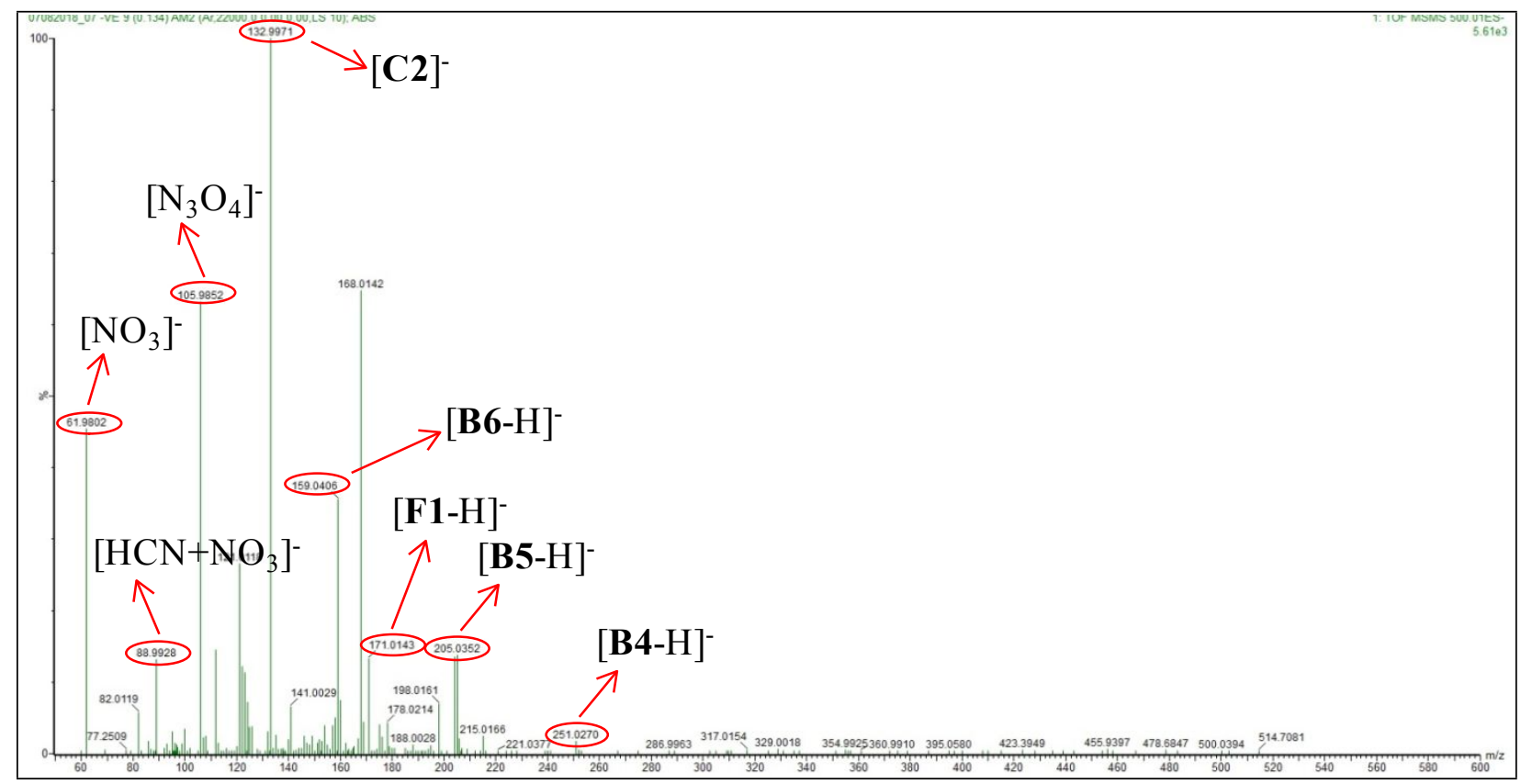

Figure S11. MS/MS of CL-20 adduct ion at m/z 500.01 


\section{TG-FTIR analysis of CL-20}

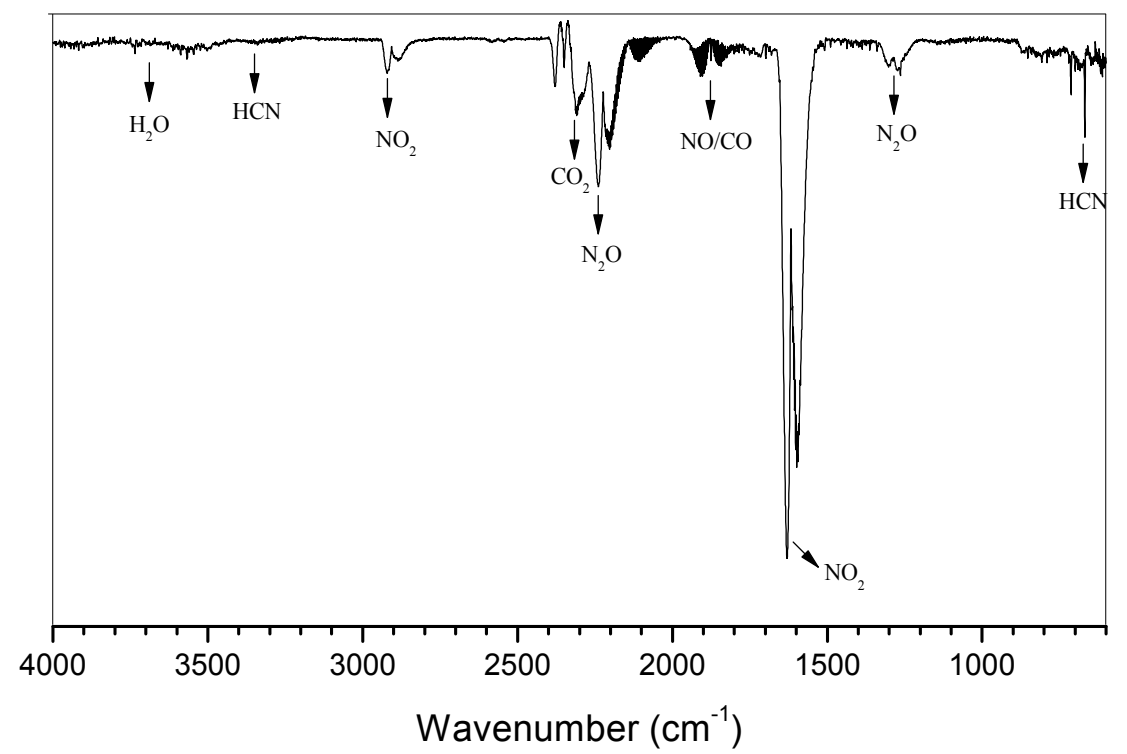

Figure S12. FTIR spectra of CL-20 thermal decomposition gas products at $226^{\circ} \mathrm{C}$

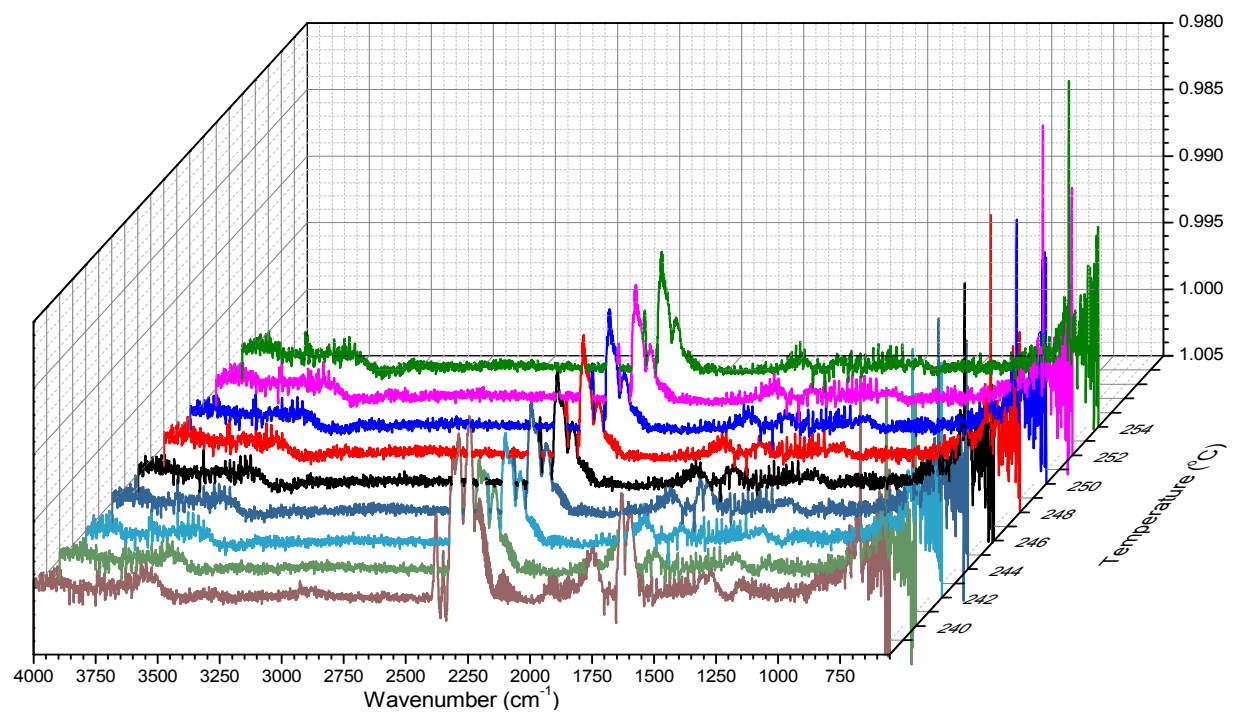

Figure S13. The 3D TG-FTIR spectra of the CL-20 thermal decomposition gas products

Table S3. Detonation Parameters of CL-20*

\begin{tabular}{ccccc}
\hline $\begin{array}{c}\text { Density } \\
(\mathrm{g} / \mathrm{cc})\end{array}$ & $\begin{array}{c}\text { Heat of Formation } \\
(\mathrm{kJ} / \mathrm{mol})\end{array}$ & $\begin{array}{c}\text { Oxygen Balance } \\
(\%)\end{array}$ & $\begin{array}{c}\text { Detonation } \\
\text { Pressure }(\mathrm{GPa})\end{array}$ & $\begin{array}{c}\text { Detonation } \\
\text { Velocity }(\mathrm{km} / \mathrm{s})\end{array}$ \\
\hline 1.9967 & 397.799 & -10.95 & 43.29 & 9.595 \\
\hline \multicolumn{5}{c}{$*$ *alculated using EXPLO5 program }
\end{tabular}




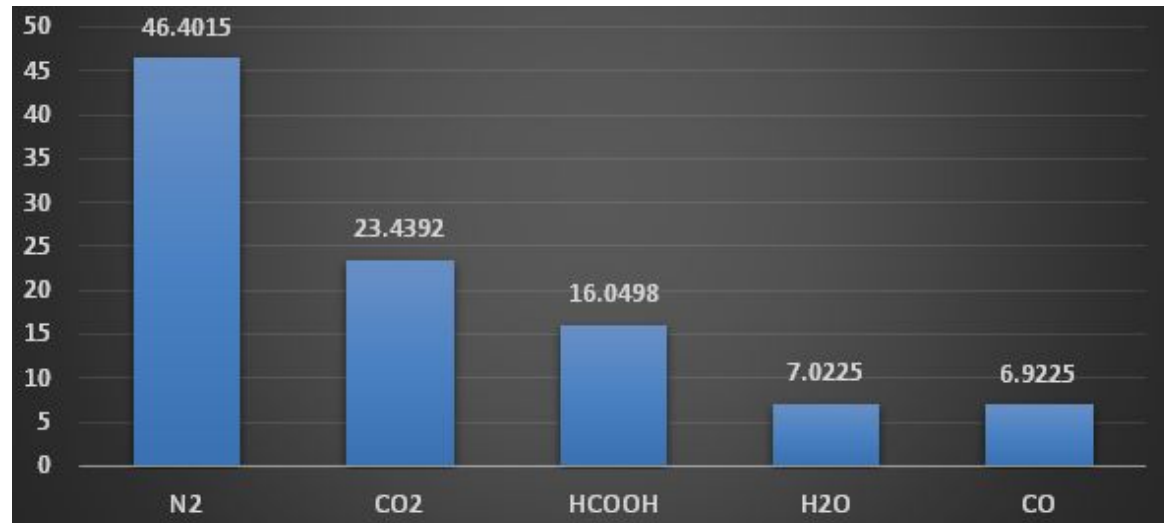

Figure S14. Molar percentage of the final detonation products of CL-20 (calculated using EXPLO5 program) 